\title{
An Assessment of Ore Waste and Dilution Resulting From Buffer/Choke Blasting in Surface Gold Mines
}

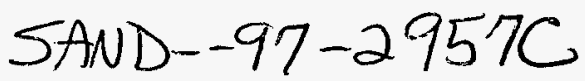

\author{
Dale S. Preece \\ Sandia National Laboratories \\ Stephen H. Chung and J. Paul Tidman \\ ICI Explosives Canada
}

\section{7}

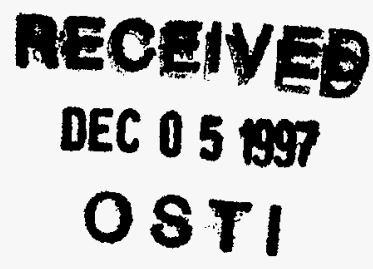

Abstract

A discrete element computer program named DMC_BLAST (Distinct Motion Code) has been under development since 1987 for modeling rock blasting (Preece \& Taylor, 1989). This program employs explicit time integration and uses spherical or cylindrical elements that are represented as circles in two dimensions (2-D). DMC_BLAST calculations compare favorably with data from actual bench blasts (Preece et al, 1993).

Buffer/Choke blasting is commonly used in surface gold mines to break the rock and dilate it sufficiently for ease of digging, with the assumption of insignificant horizontal movement. The blast designs usually call for relatively shallow holes/benches $(<11 \mathrm{~m})$ with small blastholes $(\sim 165 \mathrm{~mm})$, small burdens and spacings $(<5 \mathrm{~m}$ ), often with $50 \%$ or more of the hole stemmed. Control of blast-induced horizontal movement is desired because the ore is assayed in place from the blasthole drill cuttings and digging polygons of ore and waste are laid out before the blast. Horizontal movement at the ore/waste boundary can result in dilution of the ore or loss of ore with the waste.

The discrete element computer program DMC_BLAST has been employed to study spatial variation of horizontal rock motion during buffer/choke blasting. Patterns of rock motion can be recognized from the discrete element simulations that would be difficult or impossible to recognize in the field (Preece, Tidman and Chung, 1997).

Techniques have been developed to calculate ore waste and dilution from the horizontal movement predicted by DMC_BLAST. Four DMC_BLAST simulations of buffer blasting have been performed. The blasts are identical except that the burden and spacing are systematically varied which also changes the powder factor. Predictions of ore waste or dilution are made for each burden in the blast, assuming no horizontal movement, to illustrate the spatial variation observed. A simple correction is applied wherein the average horizontal movement of each burden is factored into the computation of ore waste or dilution.

\footnotetext{
*This work was performed at Sandia National Laboratories and funded by ICI Explosives USA. Sandia is a multiprogram laboratory operated by Sandia Corporation, a Lockheed Martin Company, for the United States Department of Energy under Contract No. DE-AC04-94AL85000.
}

Published in the Proceedings of the 24th Annual Conference on Explosives and Blasting Technique, International Society of Explosives Engineers, Feb. 8-11, 1998, New Orleans, LA. 


\section{DISCLAIMER}

This report was prepared as an account of work sponsored by an agency of the United States Government. Neither the United States Government nor any agency thereof, nor any of their employees, makes any warranty, express or implied, or assumes any legal liability or responsibility for the accuracy, completeness, or usefulness of any information, apparatus, product, or process disclosed, or represents that its use would not infringe privately owned rights. Reference herein to any specific commercial product, process, or service by trade name, trademark, manufacturer, or otherwise does not necessarily constitute or imply its endorsement, recommendation, or favoring by the United States Government or any agency thereof. The views and opinions of authors expressed herein do not necessarily state or reflect those of the United States Government or any agency thereof. 


\section{Buffer/Choke Blasting}

Buffer/choke blasting is used in surface gold mines around the world to fragment the rock and dilate it sufficiently for ease of digging. The term buffer or choke blasting refers to the fact that the shot is directed toward in-place rock rather than toward a free face as is done in surface coal mining or quarry blasting. Buffer blast designs usually call for relatively shallow holes/benches $(<11 \mathrm{~m}$.) with small blastholes $(\sim 165 \mathrm{~mm})$ small burdens and spacings $(<5 \mathrm{~m}$.) often with $50 \%$ or more of the hole stemmed. Control of blast-induced horizontal movement is desired because the ore is assayed in place from the blasthole drill cuttings and digging polygons of ore and waste are laid out before the blast. Horizontal movement at the ore/waste boundary can result in wasting some of the ore or diluting it with waste. An example buffer blast during initiation (detonating cord) and detonation is shown in Figure 1. Even though this blast has free faces the initiation sequence is not designed to optimize movement of the free face. Initiation of the blast is toward the in-place rock or buffer.

The muck-pile resulting from the blast depicted in Figure 1 is presented in Figure 2. This blast had a relatively high powder factor which resulted in considerable movement of the material. At this mine, with large ore digging polygons, this is not deemed to cause a problem.

\section{Modeling of Buffer Blasting Using DMC_BLAST}

This study includes four buffer blast simulations using DMC_BLAST, one of which is shown in Figure 3. Blast design parameters are presented in Tables 1 and 2. Each of the four blasts has 16 rows of blastholes and are identical except for the variation of the burden and spacing which also changes the powder factor as indicated in Table 2. Figure 3 shows the calculated rock movement induced by the blast with burden and spacing of $4.0 \mathrm{~m}$, resulting in a powder factor of $0.786 \mathrm{~kg} / \mathrm{m}^{3}$. The same simulation with the burdens illustrated at the beginning and end of the blast are shown in Figure 4.

Muck-pile profiles from each of the four blasts are shown in Figure 5. Since the 3 X 3 pattern has the most energy per unit mass, it dilates the rock more and creates a higher, and probably more easily excavated, muck-pile. A decrease in muck-pile height with increasing pattern size (decreasing powder factor) can be seen in Figure 5.

\section{Calculation of Ore Waste and/or Dilution}

Based on ease of excavation alone, it would seem evident that the smaller pattern would be preferable. However, smaller patterns with larger powder factors tend to induce much more horizontal motion to the rock which results in more ore dilution or waste. As mentioned previously ore and waste digging polygons are surveyed after the blast but are based on pre-blast rock assay data. An algorithm has been developed for post-processing DMC_BLAST simulations to calculate the amount of rock that has moved across each burden line as illustrated in Figure 6. As in all of the blasts treated in this study, initiation of the blastholes is from right to left in this figure. Rock tends to be pushed opposite to the direction of initiation since that is where space has been opened up by detonation of the previous rows of blastholes. The pattern illustrated in Figure 6, where the central portion (vertically) of each burden moves the most, is typical of most of the rows. This occurs because frictional resistance limits movement at the bottom of 
the blastholes and explosive loading does not occur in the stemming region at the top. Some differences to this pattern occur on the first and last few rows as illustrated in Figure 4.

The final location of the burdens as seen in Figures 4 and 6 indicate that excavation of the blasted material in two $5 \mathrm{~m}$ lifts might prove optimal. The first lift would be excavated from right to left with a face angle of $45^{\circ}$. The second lift could be excavated from left to right, also with a face angle of $45^{\circ}$. Thus, excavation of the two lifts would be along the natural boundaries between burdens in the muck-pile. Closer examination of this type of excavation scheme will be the topic of further research.

A prediction of the ore waste or dilution for each burden is performed in a manner similar to that shown in Figure 6 where a line is located on the front of burden 7 and any material that has crossed that line is accounted for as waste or dilution, depending on the circumstances. If burdens 4, 5 and 6 are ore; burdens 7,8 and 9 are waste; and excavation is from right to left, then all of the material from burdens 7,8 and 9 that is to the right of the angle-of-repose line will cause dilution. This means that the material will be excavated as ore and sent to the mill for processing. The situation could be reversed with burdens 4,5 and 6 being waste and burdens 7,8 and 9 being ore. In this case, with the same mining direction, ore from burdens 7,8 and 9 would be excavated as waste.

Vertical ore/waste boundaries are assumed for the purposes of this study. This is usually the assumption since the assay is made from drill cuttings on the surface and the depth of the cut (hole depth) is relatively shallow. It is straight forward to do dilution/waste calculations with dipping ore/waste boundaries if that sort of detail were available.

Figure 7 shows the percent of burden wasted or diluted versus burden number. Values higher than $100 \%$ are possible because material with higher burden numbers has also moved to the right of the angle-ofrepose line. The angle-of-repose can be specified by the user. In these calculations it is assumed to be $70^{\circ}$. Ore waste or dilution for the $3.0 \times 3.0 \mathrm{~m}$ pattern is as high as $220 \%$ of the burden volume. An estimate of the actual amount of material involved can be obtained by multiplying the burden by the hole depth to give the burden area which in turn can be multiplied by the length along a digging polygon resulting in a volume. The burden volume multiplied by the percentages of waste or dilution from Figure 7 gives the actual amount of material incorrectly being sent to the mill or waste pile. If a 16 row blast with a $3.0 \mathrm{X}$ $3.0 \mathrm{~m}$ pattern is assumed to be 8 rows wide with one ore/waste contact at row 9 , then $6.3 \%$ of the entire blast is wasted or diluted for the $3.0 \times 3.0 \mathrm{~m}$ pattern.

A simple correction would move the digging polygons opposite the direction of initiation, in this case to the right, by the average burden movement. Average burden movement as a function of burden number is shown in Figure 8 for the four cases being considered in this study. Figure 8 illustrates decreasing horizontal motion with increasing pattern size (decreasing powder factor) and increasing horizontal motion in the direction of initiation. When this movement is factored into the computation of waste or dilution the data shown in Figure 9 is obtained. Figure 9 can be compared directly with Figure 7 to see the effect of this correction method. All of the percentages of waste or dilution are reduced by the correction, but the reduction is more significant for the smaller blasting patterns. For the example given above this correction reduces the waste or dilution from $6.3 \%$ to $4.5 \%$. More work needs to be done determine an optimal correction procedure. 


\section{Conclusions}

A study has been performed to quantify the amount of waste or dilution of ore resulting from horizontal movement of rock during buffer blasting. Four different cases were studied with only the powder factor being varied. Algorithms for post-processing DMC_BLAST simulations for waste or dilution at each burden have been developed. Use of this algorithm on the four cases of this study indicates a significant increase in waste or dilution with increasing powder factor (decreasing pattern size). The ability to quantify waste and dilution predictions for this type of blasting makes available a powerful tool that can be used to optimize mining operations in surface gold mines. This computational technique will see significant use in the future and will continue to be developed.

\section{References}

Preece, D. S. and Taylor, L. M., 1989, Complete Computer Simulation of Crater Blasting Including Fragmentation and Rock Motion, Proceedings of the Fifth Annual Symposium on Explosives and Blasting Research, Society of Explosives Engineers, New Orleans, LA.

Preece, D. S., Burchell, S. L., and Scovira, D. S., 1993, Coupled Explosive Gas Flow and Rock Motion Modeling With Comparison to Bench Blast Field Data, Proceedings of the Fourth International Symposium on Rock Fragmentation by Blasting, Technical University, Vienna, Austria.

Preece, D. S., Tidman, J. P., and Chung, S. H., 1997, Expanded Rock Blast Modeling Capabilities of DMC_BLAST, Including Buffer Blasting, Proceedings of the Thirteenth Annual Symposium on Explosives and Blasting Research, Las Vegas, NV. 


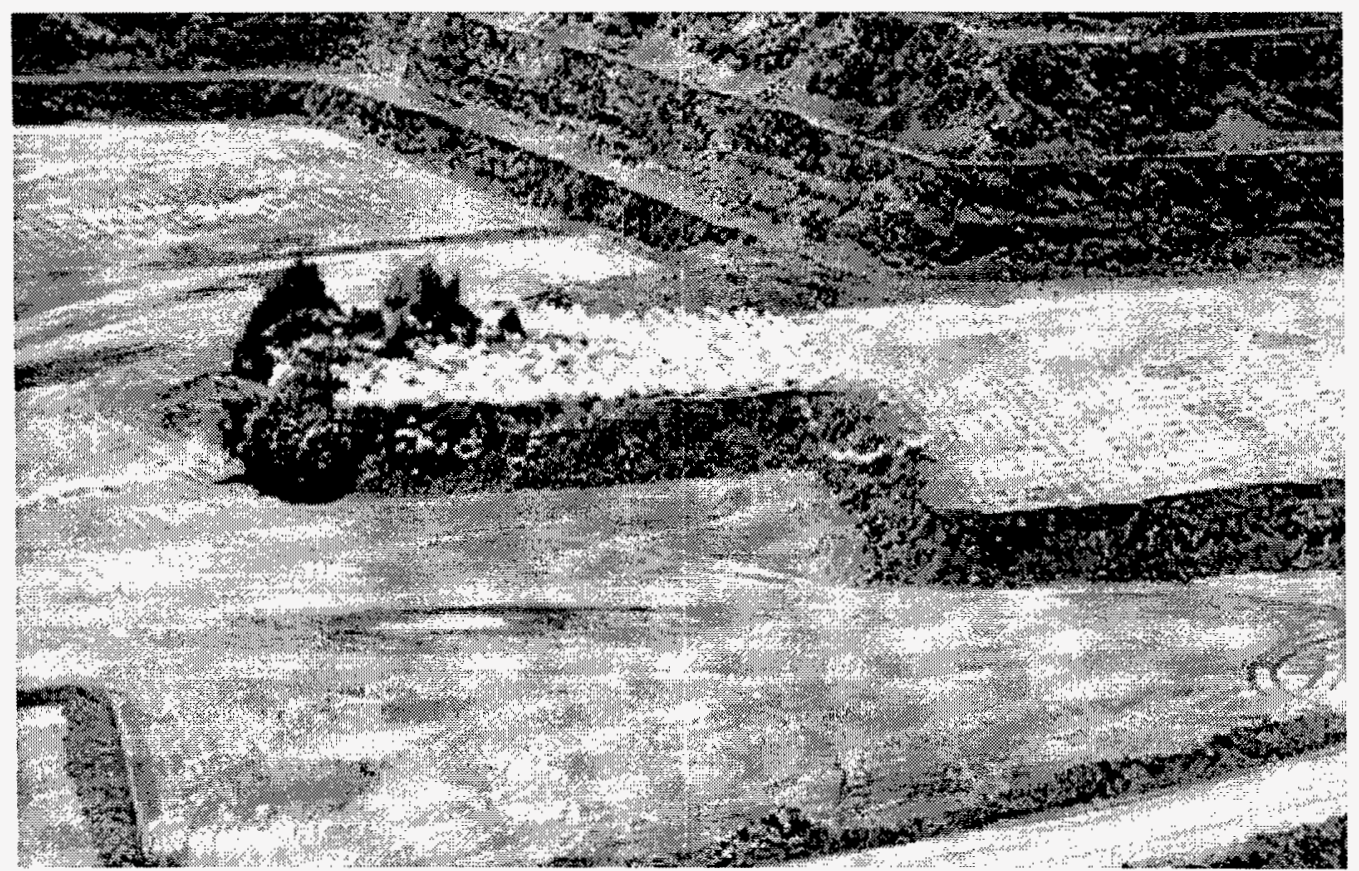

Figure 1: Buffer blast during initiation (detonating cord) and detonation of the blastholes.

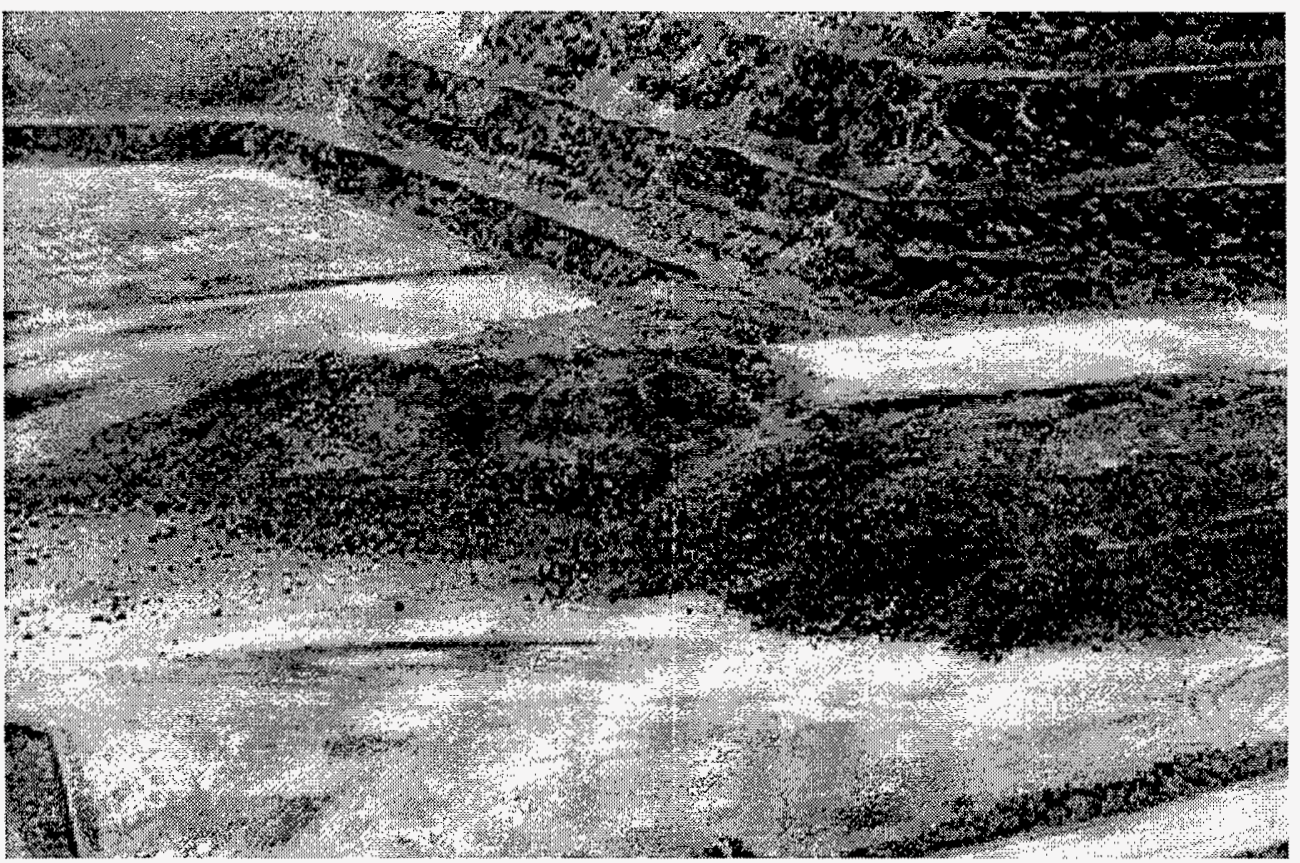

Figure 2: Muck-pile produced by blast shown in Figure 1. 


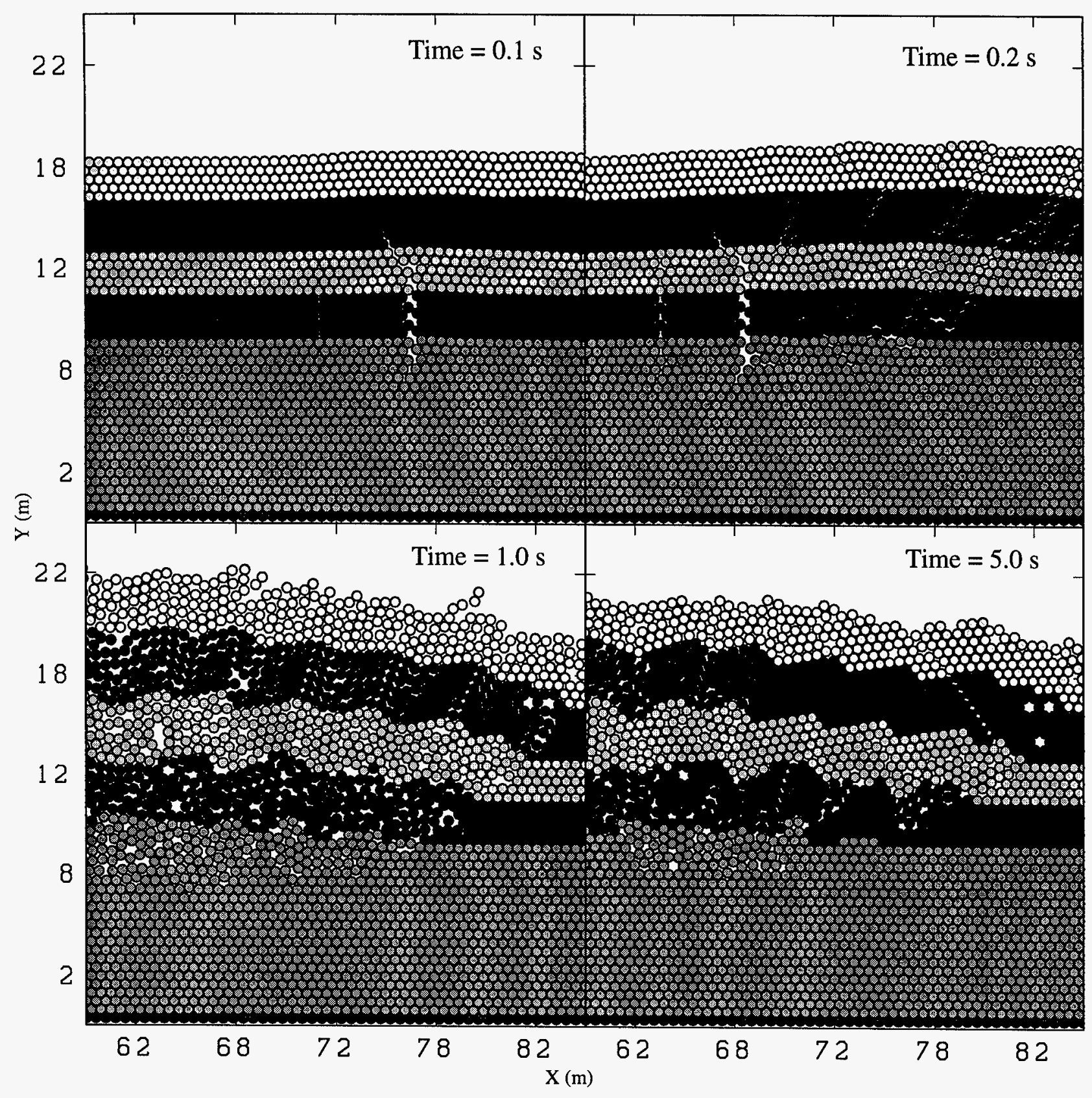

Figure 3: Zoom in on first 6 rows of DMC_BLAST simulation of 16 row buffer blast, $4.0 \times 4.0 \mathrm{~m}$ pattern. Geologic layering displayed in gray scale. 
Table 1: Blast Design Parameters

\begin{tabular}{|l|l|}
\hline \multicolumn{1}{|c|}{ Parameter } & \multicolumn{1}{c|}{ Value } \\
\hline \hline Hole Diameter & $165 \mathrm{~mm}$ \\
\hline Hole Depth & $10 \mathrm{~m}$ \\
\hline Stemming Length & $5.18 \mathrm{~m}$ \\
\hline Explosive Length & $4.82 \mathrm{~m}$ \\
\hline Explosive Type & Heavy ANFO 30/70 \\
\hline Explosive Density & $1.22 \mathrm{~g} / \mathrm{cm}^{3}$ \\
\hline Number of Rows / Delay & $16 / 42 \mathrm{~ms}$ \\
\hline
\end{tabular}

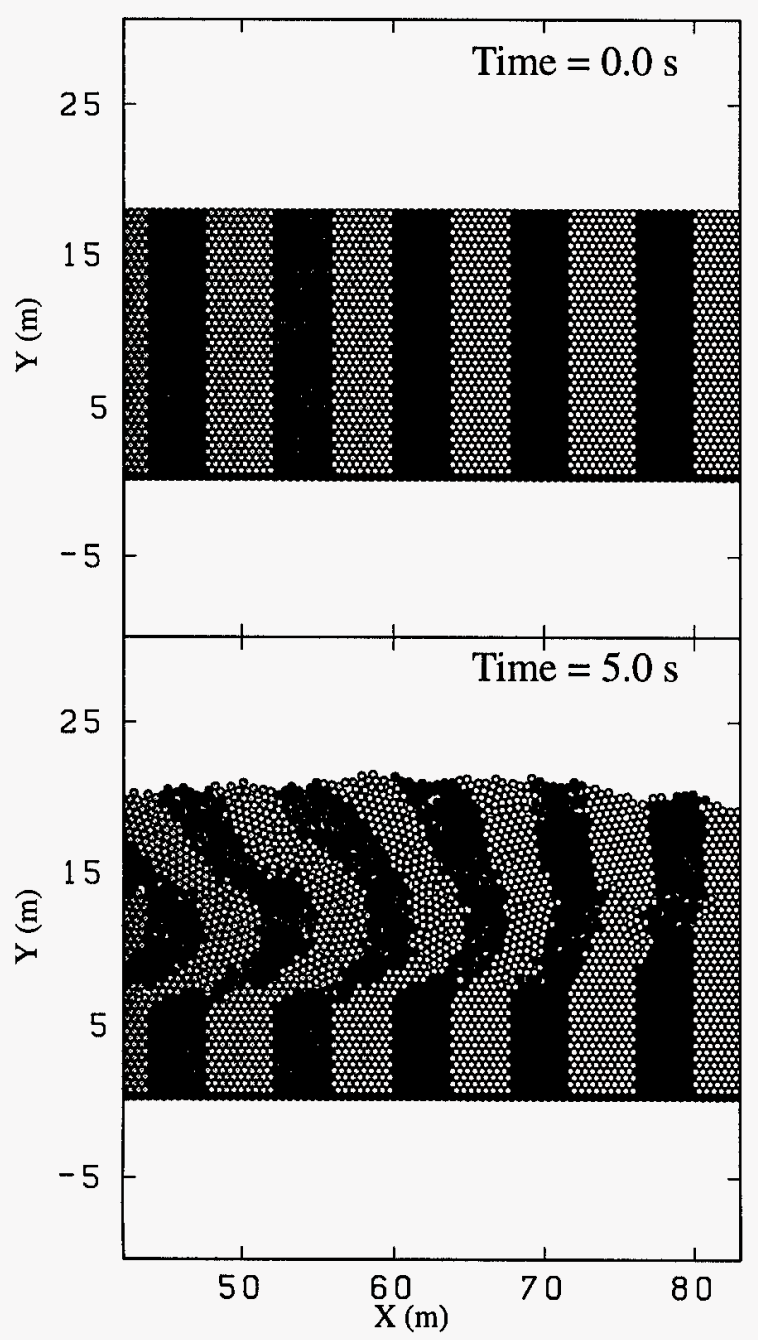

Table 2: Blasting Pattern Vs. Powder Factor

\begin{tabular}{|c|c|}
\hline Pattern Size (m) & Powder Factor $\mathrm{kg} / \mathrm{m}^{3}$ \\
\hline \hline $3.0 \times 3.0$ & 1.397 \\
\hline $3.5 \times 3.5$ & 1.026 \\
\hline $4.0 \times 4.0$ & 0.786 \\
\hline $4.5 \times 4.5$ & 0.620 \\
\hline
\end{tabular}

Figure 4: Horizontal distortion of burdens for DMC_BLAST simulation shown in Figure 3. This blast has a $4.0 \times 4.0 \mathrm{~m}$ pattern and a powder factor of $0.786 \mathrm{~kg} / \mathrm{m}^{3}$ (Table 2). Burdens are shown in gray scale. 


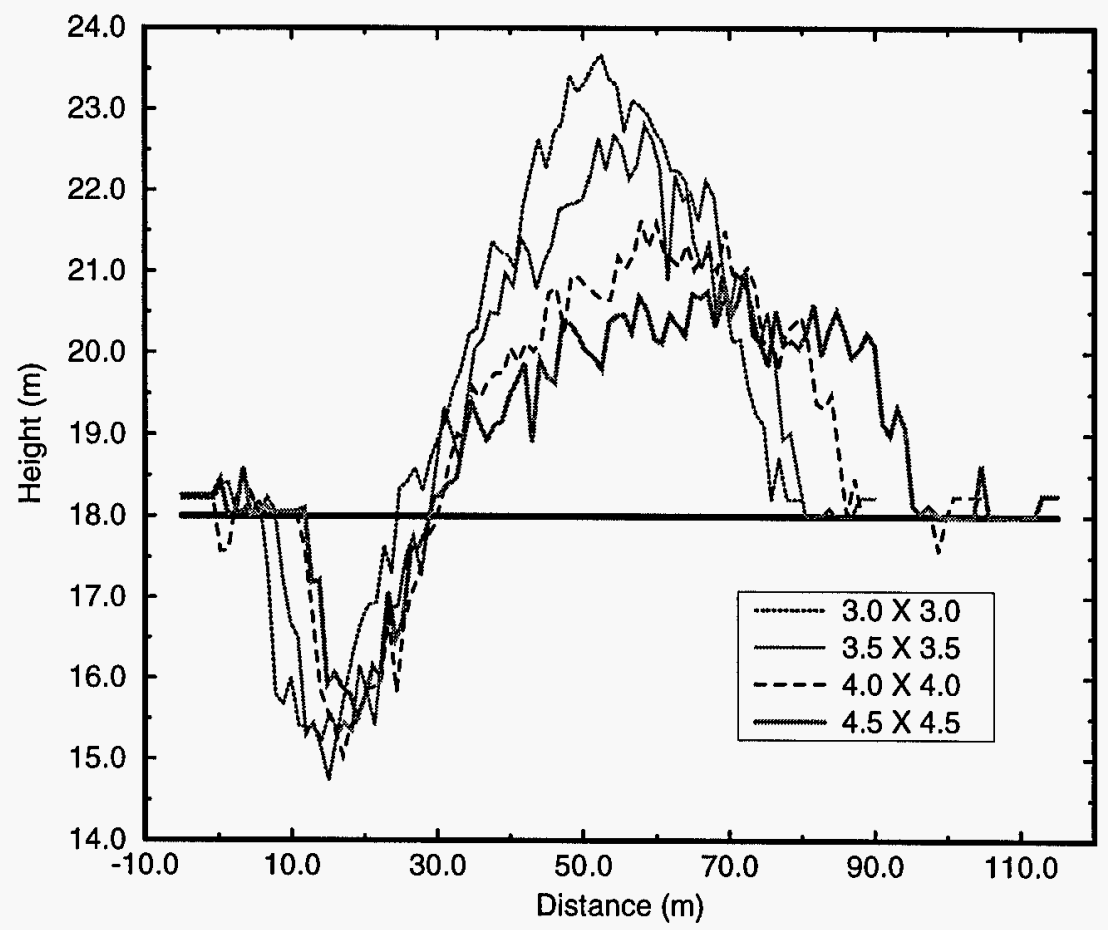

Figure 5: Muck-pile profiles calculated by DMC_BLAST for the four blasting patterns treated in this study.

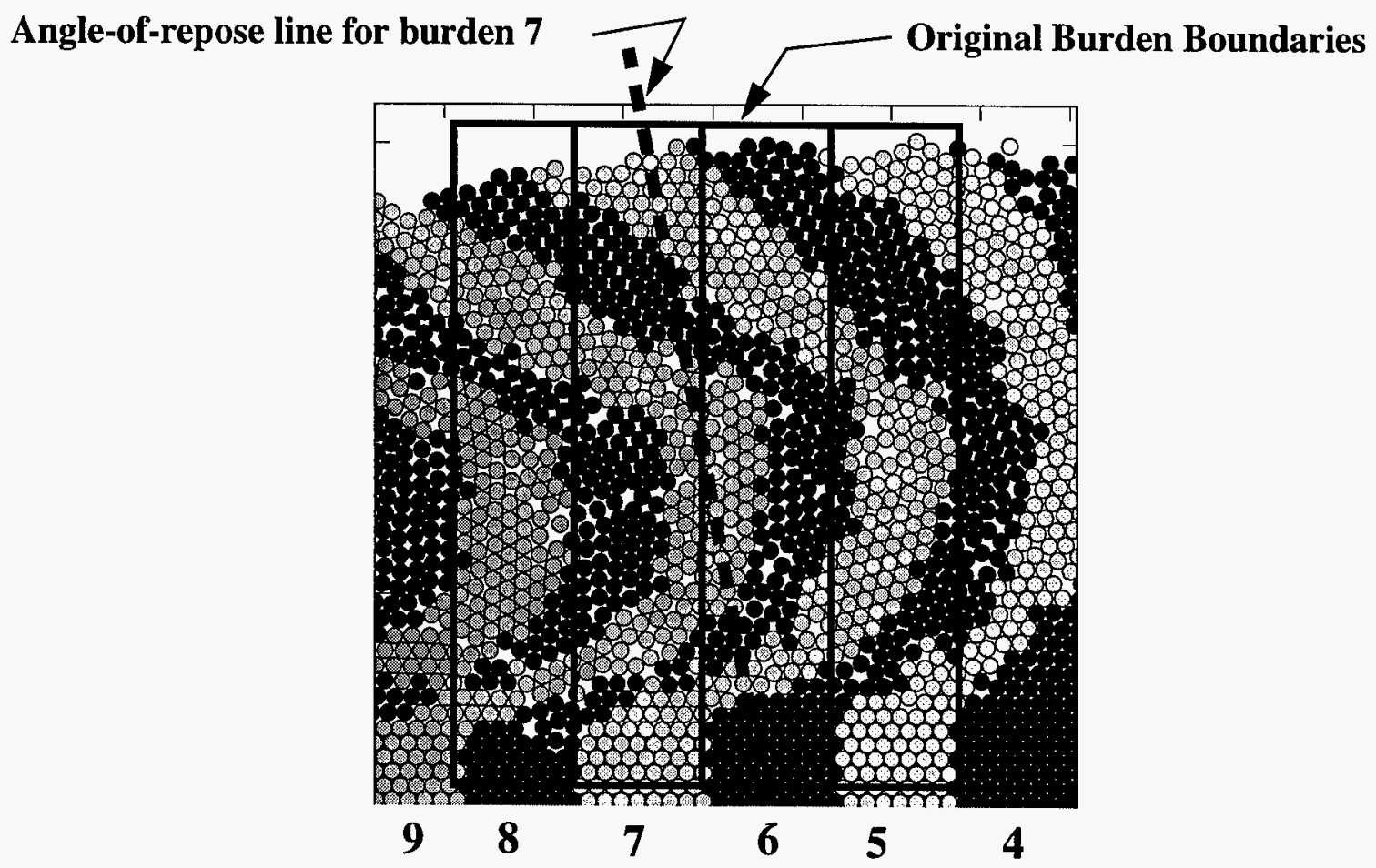

Figure 6: Example rock movement calculation. Any particles from burden 7 or higher that are right of the angle-of-repose line are considered as waste or dilution, depending on the direction of excavation. Portions of burdens 7,8 , and 9 are right of the line. 


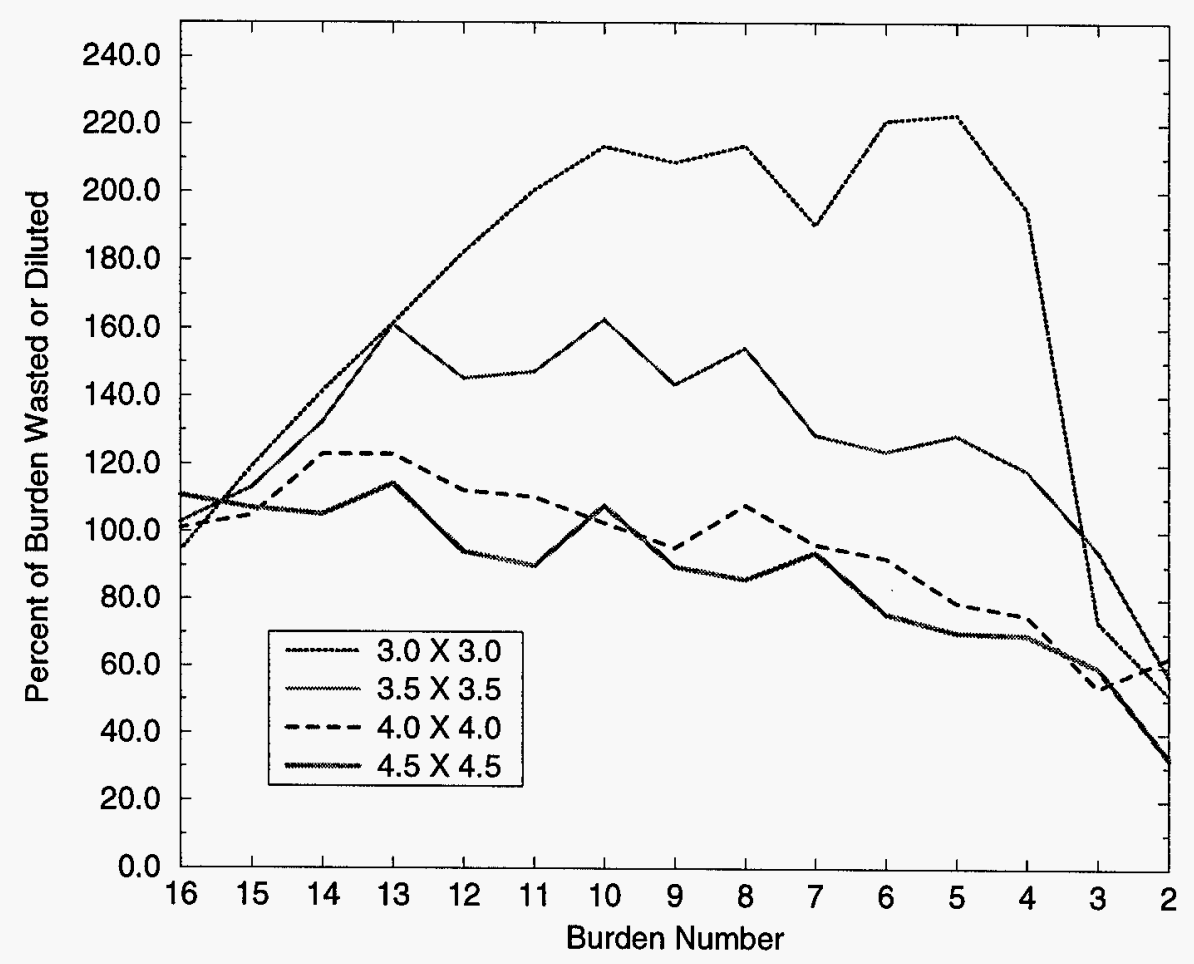

Figure 7: Percent of burden wasted or diluted versus burden, number according to criteria illustrated in Figure 6.

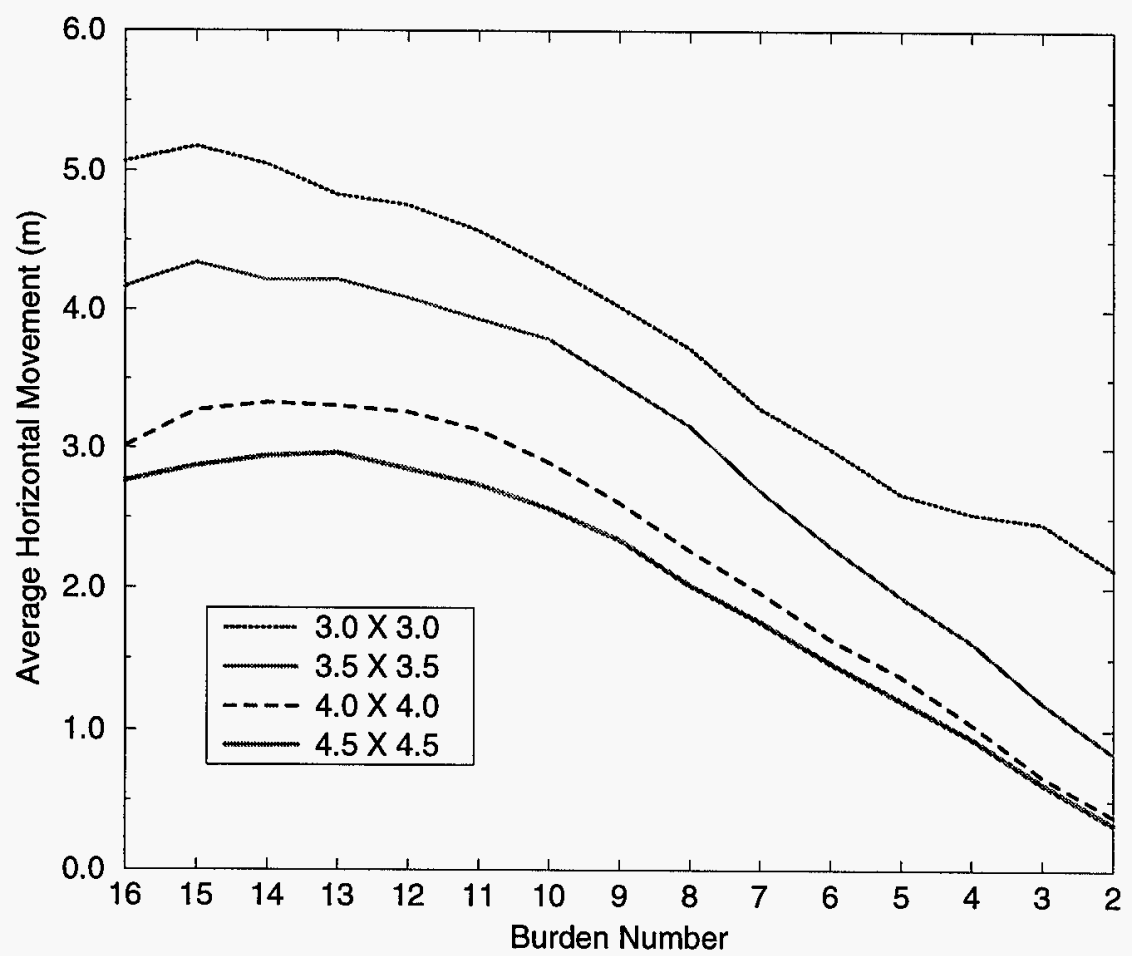

Figure 8: Average horizontal movement of each burden. 


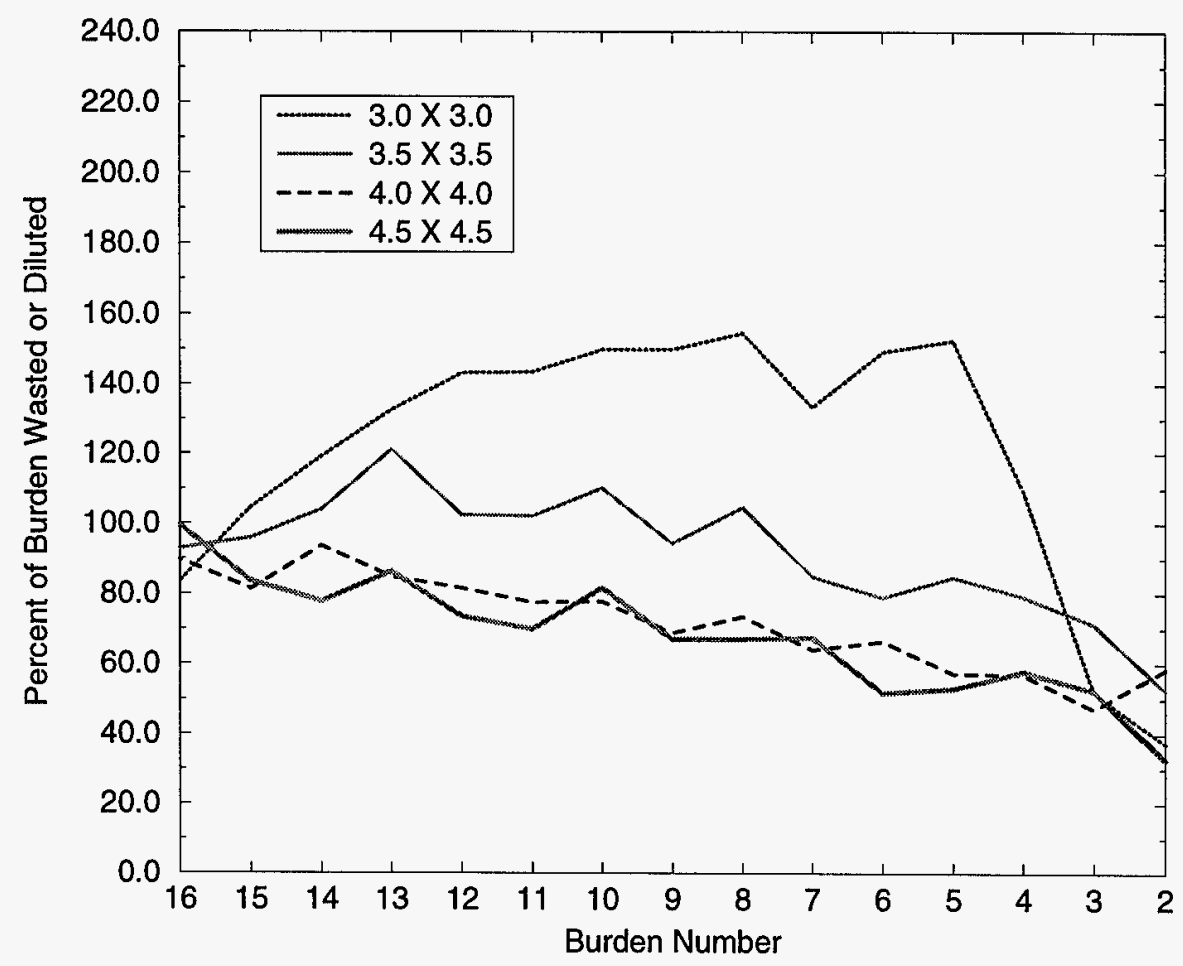

Figure 9: Percent of burden wasted or diluted versus burden number computed with the angle-of-repose line shifted to the right by the average burden movement shown in Figure 8. 
M98001366

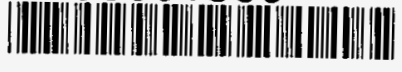

$\frac{\text { Report Number (14) SAND }-97-29570}{\text { CONF-980210 }}$

subl. Date (11) $\quad 1997 / 2$

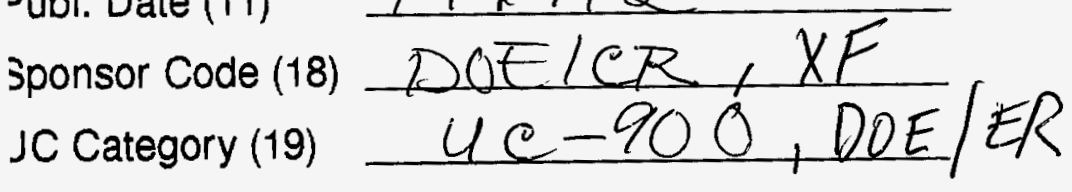

DOE 